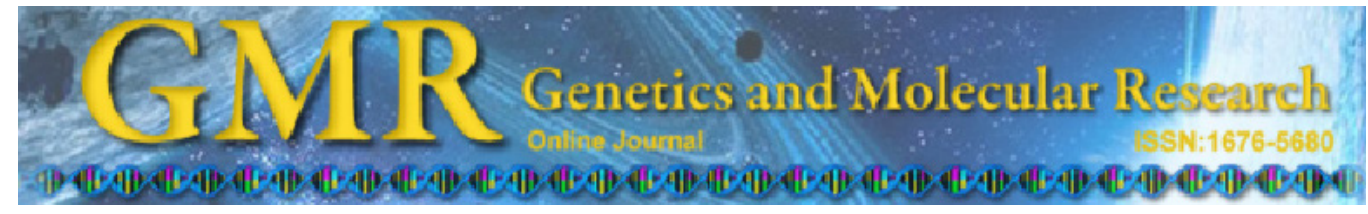

Methodology

\title{
Molecular cytogenetic characterization of the Aegilops biuncialis karyotype
}

\author{
J. Wang ${ }^{1}$, W. Zhang ${ }^{1,2}$, H. Zhao ${ }^{3}$, F.R. Li ${ }^{1}$, Z.G. Wang ${ }^{1}$, J. Ji ${ }^{1,2}$, \\ X.Q. Zhang' ${ }^{2}$ D.W. Wang ${ }^{2}$ and J.M. Li ${ }^{1,2}$ \\ ${ }^{1}$ Center for Agricultural Resources Research, \\ Institute of Genetics and Developmental Biology, \\ Chinese Academy of Sciences, Shijiazhuang, China \\ ${ }^{2}$ State Key Laboratory of Plant Cell and Chromosome Engineering, \\ Chinese Academy of Sciences, Beijing, China \\ ${ }^{3}$ College of Biological Science and Engineering, \\ Hebei University of Science and Technology, Shijiazhuang, China \\ Corresponding author: J.M. Li \\ E-mail:1jm@ms.sjziam.ac.cn
}

Genet. Mol. Res. 12 (1): 683-692 (2013)

Received April 24, 2012

Accepted October 4, 2012

Published March 11, 2013

DOI http://dx.doi.org/10.4238/2013.March.11.16

\begin{abstract}
Aegilops biuncialis can be hybridized with wheat (Triticum spp) and has been used for wheat breeding and genetic studies. The A. biuncialis karyotype $\left(\mathrm{U}^{\mathrm{b}} \mathrm{U}^{\mathrm{b}} \mathrm{M}^{\mathrm{b}} \mathrm{M}^{\mathrm{b}}\right)$ was investigated based on three $A$. biuncialis accessions grown in China. Two pairs of SAT chromosomes were identified as $1 \mathrm{U}^{\mathrm{b}}$ and $5 \mathrm{U}^{\mathrm{b}}$, with a karyotype formula of $2 n=4 x=$ $28=14 \mathrm{~m}+10 \mathrm{sm}+4 \mathrm{st}$. Fluorescence in situ hybridization (FISH) and C-banding approaches were used to analyze the $A$. biuncialis accession chromosomes at the mitotic stage. Based on the C-banding and FISH patterns, all $\mathrm{U}^{\mathrm{b}}$ and $\mathrm{M}^{\mathrm{b}}$ chromosomes could be discriminated simultaneously; the three $A$. biuncialis accessions exhibited similar patterns, suggesting a common origin. The $\mathrm{U}^{\mathrm{b}}$ genome from $A$. biuncialis resembled the $\mathrm{U}$ genome in the diploid species $A$. umbellulata, and it may be related to the tetraploid species containing the $\mathrm{U}$ genome. The $\mathrm{M}^{\mathrm{b}}$ genome had some differences compared to the $\mathrm{M}$ genome in the diploid species
\end{abstract}


A. comosa, and it may be related to the tetraploid species possessing the $\mathrm{M}$ genome. A generalized ideogram was proposed for the $A$. biuncialis genome, which could be useful for standardized and accurate identification of the A. biuncialis karyotype and chromosomes.

Key words: Aegilops biuncialis; Chromosome; Karyotype; C-banding; Fluorescence in situ hybridization

\section{INTRODUCTION}

The genus Aegilops comprises 11 diploid, 10 tetraploid, and 2 hexaploid species. Based on the C, D, S, U, and M pivotal genomes, Aegilops is classified into Polyeides, Cylindropyrum, Vertebrata, Ambylopyrum, Comopyrum, and Sitopsis sections (van Slageren, 1994). Aegilops species are the closest relatives of the diverse Triticum genus and present a reservoir of useful traits for improving the agronomic traits of wheat. A number of pest- and diseaseresistant genes of Aegilops have been transferred to wheat (Triticum aestivum L.) through wide hybridization and chromosome engineering (Riley et al., 1968; Dhaliwal et al., 2002).

Aegilops biuncialis is generally associated with the Polyeides section. The species in this section are annual and have tetraploid genomes $\left(\mathrm{U}^{\mathrm{b}} \mathrm{U}^{\mathrm{b}} \mathrm{M}^{\mathrm{b}} \mathrm{M}^{\mathrm{b}}, 2 n=4 x=28\right)$. The $\mathrm{U}^{\mathrm{b}}$ genome is donated by an $A$. umbellulata diploid progenitor $(2 n=2 x=14, \mathrm{UU})$, whereas the modified $\mathrm{M}^{\mathrm{b}}$ genome is donated by $A$. comosa $(2 n=2 x=14$, MM) (Resta et al., 1996; Badaeva et al., 2004). Some $A$. biuncialis accessions are highly resistant to barley yellow dwarf disease (Makkouk et al., 1994), and others have superior rust resistance (Dhaliwal et al., 2002). A. biuncialis genotypes from dry environments generally have a drought tolerance better than that of wheat. These genotypes may be important for improving drought tolerance in wheat via intergenetic crossing (Molnár et al., 2004).

The early C-banding technique has been successfully used to analyze wheat genomes and chromosomes (Gill and Kimber, 1974). This approach has also been useful in the characterization of genomes and chromosomes of Aegilops species. For example, C-banding has been used to construct standard karyotypes of $A$. umbellulata, A. comosa, and A. geniculata (Friebe et al., 1995, 1996). It has also been used to detect alien chromatins in T. aestivum-A. ovatum, T. aestivum-A. squarrosa, T. aestivum-A. caudate, and T. aestivum-A. geniculata hybrids (Friebe and Heun, 1989; Friebe et al., 1992a,b, 2000).

Multicolor fluorescence in situ hybridization (FISH), based on the labeling of repetitive sequences as probes, has been developed and used extensively for Triticum chromosome identification. The repetitive sequences harbored by the plasmids pSc119.2 (Bedbrook et al., 1980; McIntyre et al., 1990), pSc74 (Bedbrook et al., 1980), pAs1 (Rayburn and Gill, 1986), pTa71 (Gerlach and Bedbrook, 1979), and pTa794 (Gerlach and Dyer, 1980) are most frequently used as probes. Owing to their excellent hybridization signal stability and intensity, the probes derived from pSc119.2 and pAs1 plasmids have gained widespread application in chromosome discrimination and alien chromatin identification in wheat-rye and wheat-barley chromosome translocations (Mukai et al., 1993; Nagy et al., 2002; Wang et al., 2004).

Both FISH and C-banding methods have been used to analyze karyotype and polygenetic relationships in A. biuncialis. Using 27 accessions of diverse origin, Badaeva (2002) and Badaeva et al. (2004) have reported detailed C-banding karyotype and FISH patterns in A. biuncialis. However, these authors failed to show the FISH patterns of the investigated 
chromosomes graphically. Using three A. biuncialis accessions, Schneider et al. (2005) have proposed an FISH pattern for all A. biuncialis chromosomes; however, they reported no corresponding C-banding results for $A$. biuncialis chromosomes.

In 2003, we hybridized these three $A$. biuncialis with common wheat and obtained 433 strains. Hence, the main objective of this study was to analyze FISH and C-banding patterns of three drought-tolerant A. biuncialis accessions concurrently, with the aim of establishing a generalized A. biuncialis ideogram for facilitating the accurate identification of its component genomes and chromatin in the wheat genetic background.

\section{MATERIAL AND METHODS}

\section{Plant materials}

The Biun 65, Biun 76, and Biun 77 A. biuncialis accessions (introduced from Institute of Crop Germplasm Resources, Chinese Academy of Agricultural Sciences, 12th South Street, Zhongguancun, Haidian District, Beijing, China) were used in this study.

\section{Chromosome preparation}

Approximately 2- to 3-cm root tips were excised and pretreated in ice water for 22 to $24 \mathrm{~h}$. They were then fixed in a freshly prepared 3:1 solution of absolute ethanol and glacial acetic acid for 1 to 7 days. The root caps were removed with a razor blade, and the small pieces of meristem were squashed in $45 \%$ acetic acid. The slides were frozen in liquid nitrogen, and the cover slips were removed with a razor blade. The slides were subsequently dehydrated through a 70,90 , and $100 \%$ ethanol series for $5 \mathrm{~min}$ each, dried overnight at room temperature, and stored at $4^{\circ} \mathrm{C}$ for further use.

\section{C-banding}

Slides were treated in $0.2 \mathrm{M} \mathrm{HCl}$ at $60^{\circ} \mathrm{C}$ for $2 \mathrm{~min}$ (in a water bath), washed in distilled water, incubated in saturated barium hydroxide solution at room temperature for $7 \mathrm{~min}$, rinsed in distilled water, and then incubated in $2 \mathrm{X}$ saline sodium citrate (SSC) at $60^{\circ} \mathrm{C}$ for $1 \mathrm{~h}$. The slides were placed directly in 1 to $5 \%$ Giemsa staining solution of phosphate buffer for up to $30 \mathrm{~min}$. The chromosome staining process was monitored until optimal staining was obtained.

\section{DNA probes}

DNA probes were prepared using the plasmids pSc119.2 (Bedbrook et al., 1980) and pAs1 (Rayburn and Gill, 1986). The DNA of the two plasmids was labeled with biotin16-dUTP (red) and digoxigenin-11-dUTP (green), respectively, via nick translation (Roche Company, Switzerland).

\section{FISH}

Denatured hybridization solution (40 $\mu \mathrm{L})$ containing $2 \mathrm{X}$ SSC, $10 \%$ dextran sulfate, 
$50 \%$ formamide, $0.1 \%$ sodium dodecyl sulfate, $0.9 \mu \mathrm{g}$ salmon sperm DNA, and $30 \mathrm{ng}$ labeled DNA probe was applied to each denatured slide and incubated at $37^{\circ} \mathrm{C}$ for $6 \mathrm{~h}$. Stringency washing was carried out in $4 \mathrm{X} \mathrm{SSC}$-Tween 20 for $10 \mathrm{~min}$ at $42^{\circ} \mathrm{C}$, and $20 \mu \mathrm{L}$ antidigoxigeninrhodamine (Roche) was applied to each slide. After incubation at $37^{\circ} \mathrm{C}$ for $1 \mathrm{~h}$, the slides were again washed in $4 \mathrm{X} \mathrm{SSC}$-Tween 20 for $20 \mathrm{~min}$ at $42^{\circ} \mathrm{C}$. The preparations were counterstained with 4,6-diamidino-2-phenylindole and examined under a Zeiss Axioskop epifluorescence microscope (Zeiss, Oberkochen, Germany). The microscope was equipped with filter 10 for fluoresce in isothiocyanate, filter 15 for Texas Red, and a triple-band filter for fluorescence in isothiocyanate, 4,6-diamidino-2-phenylindole, and Texas Red. Images were taken with a SpotCCD camera (DVC Company, USA).

\section{RESULTS}

\section{Karyotype and C-banding analysis}

Each of the three accessions of $A$. biuncialis had seven pairs each of $\mathrm{U}^{\mathrm{b}}$ and $\mathrm{M}^{\mathrm{b}}$ chromosomes and two pairs of satellite (SAT) chromosomes were identified on the $1 \mathrm{U}^{\mathrm{b}}$ and $5 \mathrm{U}^{\mathrm{b}}$ chromosomes (Figures 1A, B, and 2). The karyotype was composed of seven chromosome pairs with median centromeres (m), five pairs with submedian centromeres (sm), and two pairs with subterminal centromeres (st). The formula for the chromosome karyotype was $2 n=4 x=$ $28=14 \mathrm{~m}+10 \mathrm{sm}+4 \mathrm{st}$. The arm ratios $(\mathrm{L} / \mathrm{S})$, relative arm lengths $(\mathrm{L}+\mathrm{S})$ and arm types $(\mathrm{m}$, $\mathrm{sm}, \mathrm{st})$ of the chromosomes are listed in Table 1.

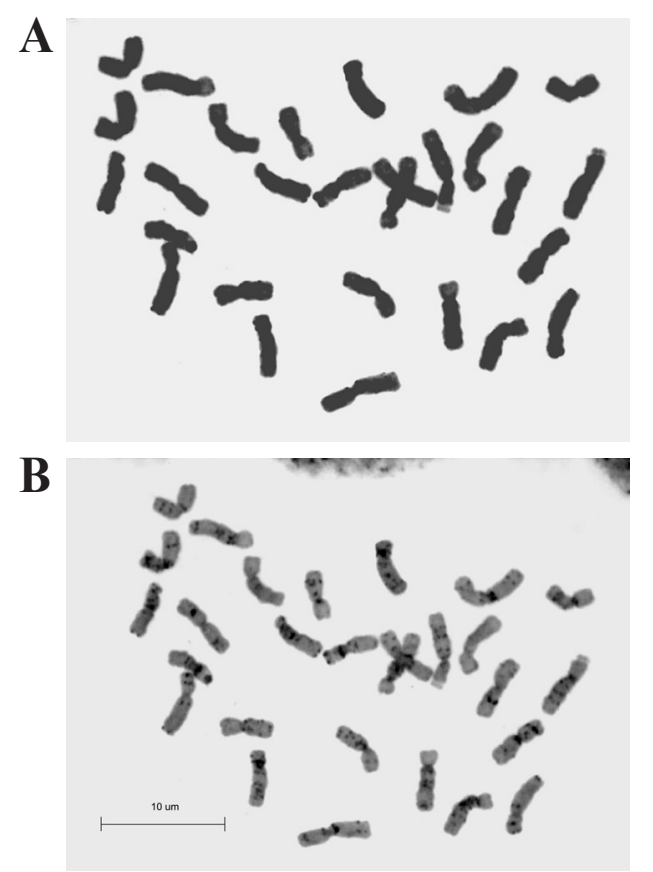

Figure 1. Mitotic metaphase chromosomes of Aegilops biuncialis accession Biun 65. A. Phase contrast. B. C-banding. 


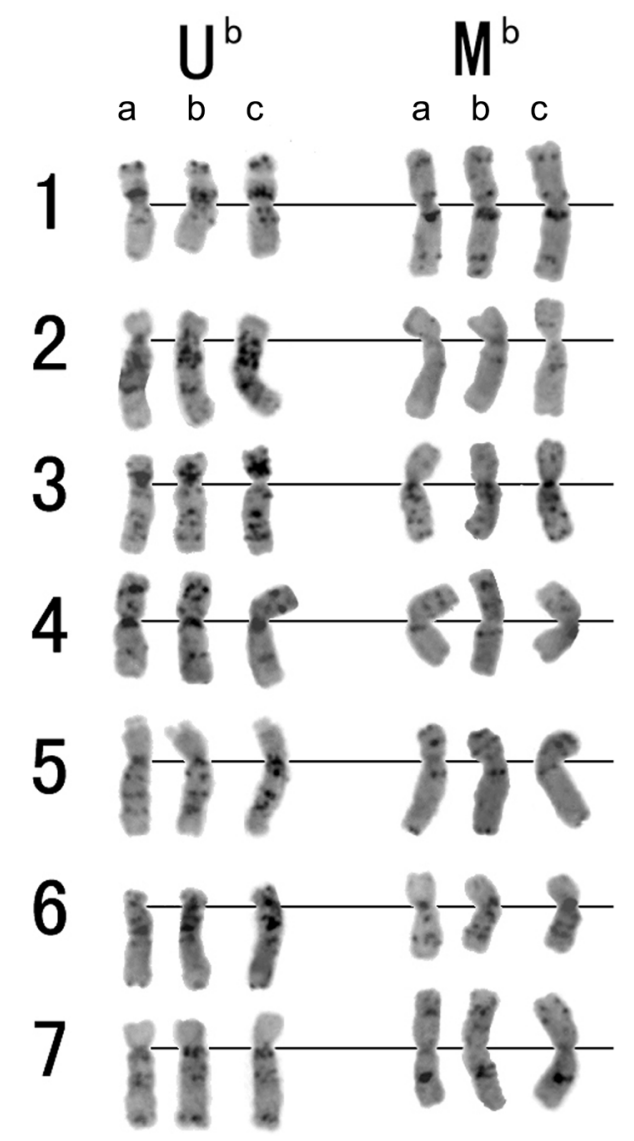

Figure 2. C-banding patterns of chromosomes in the 3 Aegilops biuncialis accessions. a. Biun 65. b. Biun 76. c. Biun 77.

Table 1. Arm ratio, relative arm length and type of Aegilops biuncialis chromosomes.

\begin{tabular}{lccc}
\hline Chromosome & Arm ratio $(\mathrm{L} / \mathrm{S})$ & Relative arm length & Type of chromosomes \\
\hline $1 \mathrm{U}^{\mathrm{b}}$ & 1.23 & 6.26 & $\mathrm{~m}$ \\
$2 \mathrm{U}^{\mathrm{b}}$ & 3.90 & 7.26 & $\mathrm{st}$ \\
$3 \mathrm{U}^{\mathrm{b}}$ & 2.61 & 6.70 & $\mathrm{sm}$ \\
$4 \mathrm{U}^{\mathrm{b}}$ & 1.45 & 7.46 & $\mathrm{~m}$ \\
$5 \mathrm{U}^{\mathrm{b}}$ & 1.74 & 8.06 & $\mathrm{sm}$ \\
$6 \mathrm{U}^{\mathrm{b}}$ & 5.51 & 6.58 & $\mathrm{st}$ \\
$7 \mathrm{U}^{\mathrm{b}}$ & 2.88 & 7.34 & $\mathrm{sm}$ \\
$1 \mathrm{M}^{\mathrm{b}}$ & 1.24 & 8.99 & $\mathrm{~m}$ \\
$2 \mathrm{M}^{\mathrm{b}}$ & 2.11 & 7.05 & $\mathrm{sm}$ \\
$3 \mathrm{M}^{\mathrm{b}}$ & 1.44 & 6.45 & $\mathrm{~m}$ \\
$4 \mathrm{M}^{\mathrm{b}}$ & 1.09 & 6.64 & $\mathrm{~m}$ \\
$5 \mathrm{M}^{\mathrm{b}}$ & 2.23 & 7.46 & $\mathrm{sm}$ \\
$6 \mathrm{M}^{\mathrm{b}}$ & 1.45 & 5.67 & $\mathrm{~m}$ \\
$7 \mathrm{M}^{\mathrm{b}}$ & 1.00 & 8.09 & $\mathrm{~m}$
\end{tabular}

$\mathrm{L} / \mathrm{S}=$ long arm length and short arm length; $\mathrm{m}=$ median centromere; $\mathrm{st}=$ subterminal centromere; $\mathrm{sm}=$ submedian centromere. 
All A. biuncialis chromosomes had identifiable C-bands (see Figure 1B). Similar Cbanding patterns were observed among the three A. biuncialis accessions (see Figure 2). A generalized C-banding ideogram was established based on measurements from 10 chromosomes of each A. biuncialis accession (Figure 3).

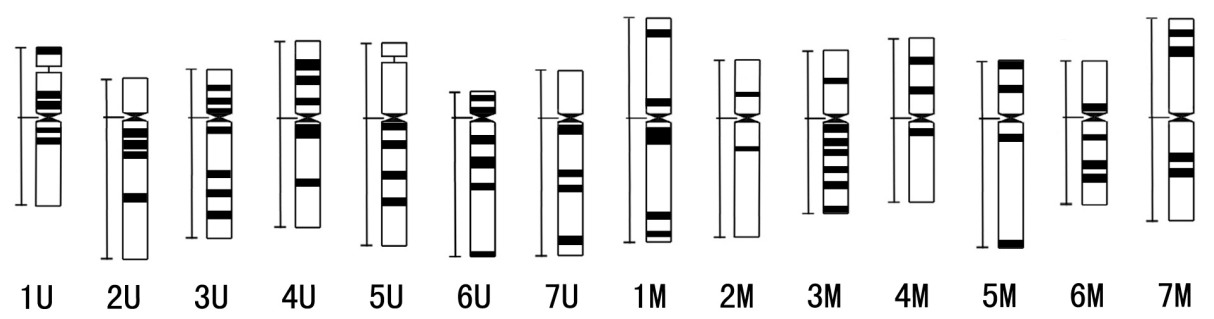

Figure 3. Generalized idiogram of the 3 Aegilops biuncialis accessions. The chromosome arm length and arm ratio data were based on the measurements of 10 chromosomes of each A. biuncialis accession.

Chromosome $1 \mathrm{U}^{\mathrm{b}}$ [arm ratio $(\mathrm{L} / \mathrm{S}), 1.2$; relative arm length $(\mathrm{L}+\mathrm{S}), 6.3$; type of chromosome, m] was an SAT chromosome with secondary constriction in the distal region of the short arm. C-bands were present on both sides of the centromere, and at the telomere of secondary constriction. Chromosome $2 \mathrm{U}^{\mathrm{b}}(\mathrm{L} / \mathrm{S}, 3.9$; L+S, 7.3; type of chromosome, st) had $\mathrm{C}$-bands on the proximal and interstitial regions of the long arm. However, chromosome $2 \mathrm{U}^{\mathrm{b}}$ had no C-bands on either the telomeres or the short arm. Chromosome $3 \mathrm{U}^{\mathrm{b}}(\mathrm{L} / \mathrm{S}, 2.6 ; \mathrm{L}+\mathrm{S}$, 6.7; type of chromosome, $\mathrm{sm}$ ) had C-bands on both sides of the centromere. Some dense Cbands were noted on the short arm of chromosome $3 \mathrm{U}^{\mathrm{b}}$. However, C-bands were completely absent on both telomeres. Chromosome $4 \mathrm{U}^{\mathrm{b}}(\mathrm{L} / \mathrm{S}, 1.5 ; \mathrm{L}+\mathrm{S}, 7.5$; type of chromosome, $\mathrm{m})$ had $\mathrm{C}$-bands on both sides of the centromere. Interestingly, three C-bands were present on the short arm and two were present on the long arm. However, no C-band was observed on the telomeres. Chromosome $5 \mathrm{U}^{\mathrm{b}}(\mathrm{L} / \mathrm{S}, 1.7 ; \mathrm{L}+\mathrm{S}, 8.1$; type of chromosome, sm) was a second SAT chromosome. Three C-bands were evenly distributed on the long arm, but no C-bands were present on the telomeres and short arm. Chromosome $5 \mathrm{U}^{\mathrm{b}}$ was easily distinguishable from SAT chromosome $1 \mathrm{U}^{\mathrm{b}}$ by its short satellite and different chromosome length. Chromosome $6 \mathrm{U}^{\mathrm{b}}(\mathrm{L} / \mathrm{S}, 5.5 ; \mathrm{L}+\mathrm{S}, 6.6$; type of chromosome, st) was easily distinguishable by its large arm ratio. C-bands were present on both sides of the centromere, and some C-bands were observed on the long arm, one of which was on the telomere. Chromosome $7 \mathrm{U}^{\mathrm{b}}(\mathrm{L} / \mathrm{S}, 2.9 ; \mathrm{L}+\mathrm{S}, 7.3$; type of chromosome, sm) had no C-bands on the short arm. Several C-bands were observed on the long arm, one of which was on the telomere.

Chromosome $1 \mathrm{M}^{\mathrm{b}}(\mathrm{L} / \mathrm{S}, 1.2 ; \mathrm{L}+\mathrm{S}, 9.0$; type of chromosome, $\mathrm{m})$ was the longest chromosome. Two C-bands were present on the short arm and three were present on the long arm, one of which was denser in the proximal region of the centromere. Chromosome $2 \mathrm{M}^{\mathrm{b}}(\mathrm{L} / \mathrm{S}$, $2.1 ; \mathrm{L}+\mathrm{S}, 7.1$; type of chromosome, sm) had two weak C-bands, with one of each in the interstitial regions of the short and long arms. Chromosome $3 \mathrm{M}^{\mathrm{b}}(\mathrm{L} / \mathrm{S}, 1.4 ; \mathrm{L}+\mathrm{S}, 6.5$; type of chromosome, $\mathrm{m}$ ) had C-bands on both sides of the centromere. More C-bands occurred on the long arm than on the short arm; only one C-band was observed on the short arm, and six C-bands were observed on the long arm. Chromosome $4 \mathrm{M}^{\mathrm{b}}(\mathrm{L} / \mathrm{S}, 1.1 ; \mathrm{L}+\mathrm{S}, 6.6$; type of chromosome, $\mathrm{m})$ had two C-bands on the short arm. One of the C-bands close to the centromere was on the 
long arm. Chromosome $5 \mathrm{M}^{\mathrm{b}}(\mathrm{L} / \mathrm{S}, 2.2 ; \mathrm{L}+\mathrm{S}, 7.5$; type of chromosome, $\mathrm{sm})$ had $2 \mathrm{C}$-bands in the proximal regions of the short and long arms. Two additional C-bands were present on both telomeres. Chromosome $6 \mathrm{M}^{\mathrm{b}}(\mathrm{L} / \mathrm{S}, 1.5 ; \mathrm{L}+\mathrm{S}, 5.7$; type of chromosome, $\mathrm{m})$ was the shortest chromosome, with C-bands on the centromere and long arm. Chromosome $7 \mathrm{M}^{\mathrm{b}}(\mathrm{L} / \mathrm{S}, 1.0$; $\mathrm{L}+\mathrm{S}, 8.1$; type of chromosome, $\mathrm{m}$ ) was a metacentric chromosome with two C-bands close to the telomere on the short arm and two notably dense C-bands at the middle of the long arm.

\section{FISH analysis}

The three A. biuncialis accessions exhibited similar FISH patterns. The sites of pSc119.2 were observed on all of the chromosomes except $6 \mathrm{U}^{\mathrm{b}}, 2 \mathrm{M}^{\mathrm{b}}$, and $3 \mathrm{M}^{\mathrm{b}}$. Similarly, pAs1 sites were found on all of chromosomes except $2 \mathrm{U}^{\mathrm{b}}, 3 \mathrm{U}^{\mathrm{b}}, 4 \mathrm{U}^{\mathrm{b}}, 3 \mathrm{M}^{\mathrm{b}}$, and $4 \mathrm{M}^{\mathrm{b}}$. With the exception of $3 \mathrm{M}^{\mathrm{b}}$, all the chromosomes had one or both of the pSc119.2 and pAs1 hybridization sites. These characteristics allowed the distinction of all chromosomes (Figure 4). A generalized FISH ideogram was established for A. biuncialis (Figure 5). The presence and absence of pSc119.2 (red bands) or pAs1 (green bands) hybridization sites and their locations on the A. biuncialis chromosomes are described below.
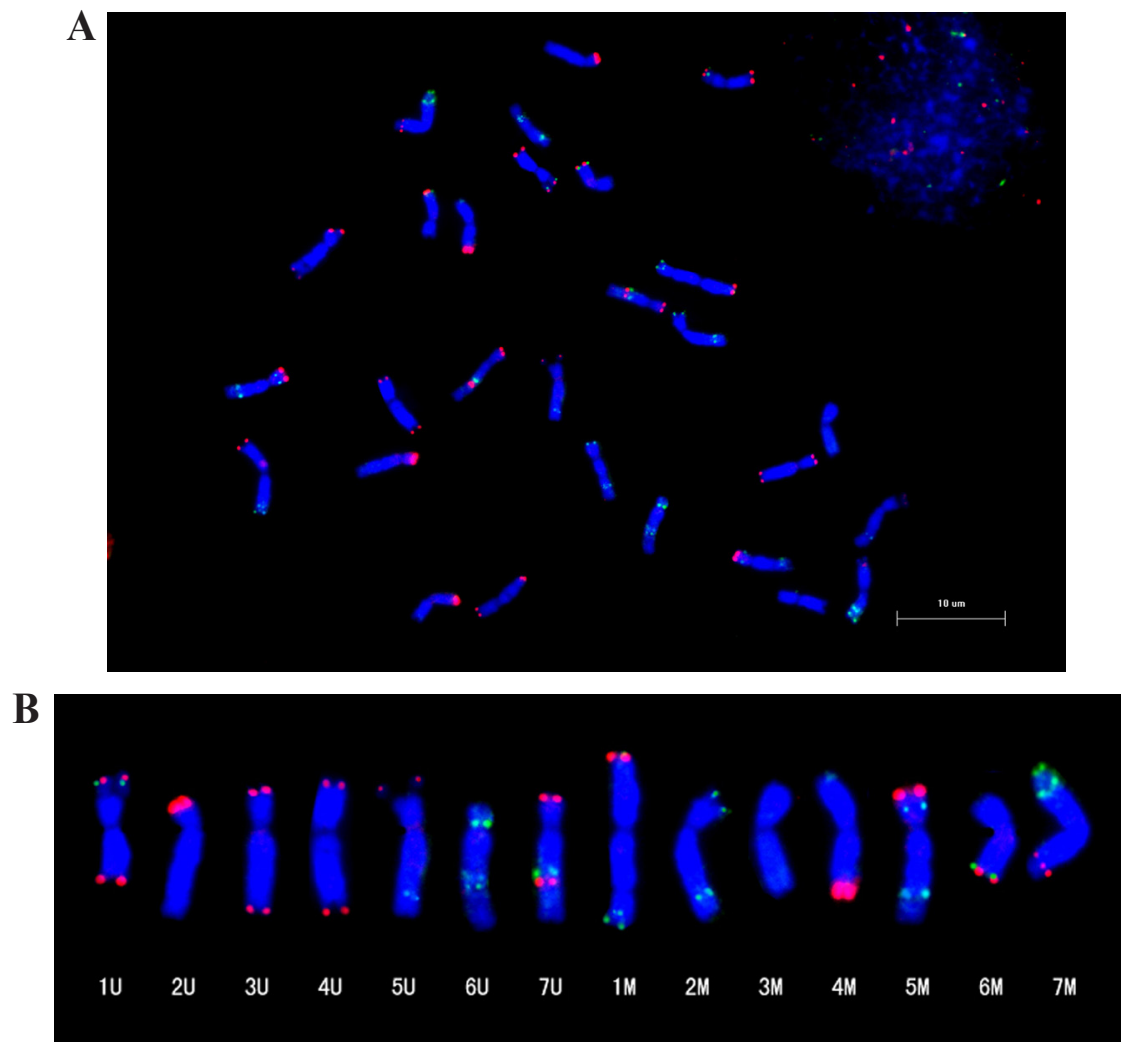

Figure 4. Fluorescence in situ hybridization (FISH) depicting the locations of pSc119.2 (red) and pAs1 (green) hybridization sites on individual somatic chromosomes of the Aegilops biuncialis accession Biun 76. A. Mitotic metaphase chromosomes. B. FISH patterns. 

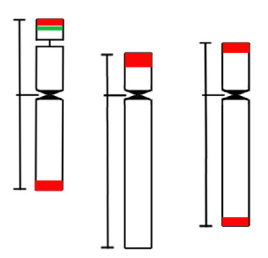

$1 \mathrm{U}$

$2 \mathrm{U}$ $3 \mathrm{U}$

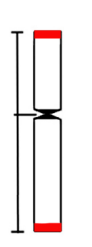

$4 U$

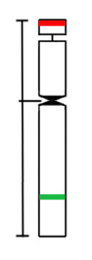

$5 U$

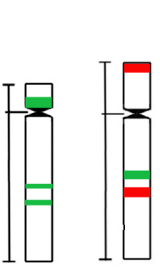

$6 U$

70

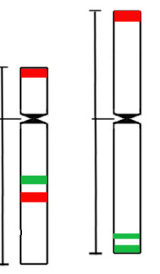

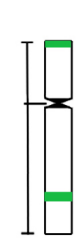
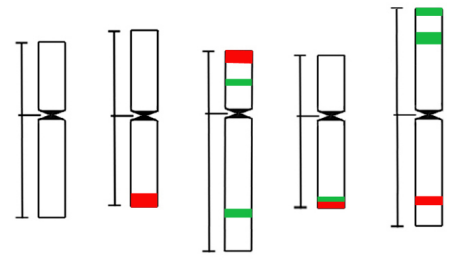

$5 M \quad 6 M \quad 7 M$

Figure 5. Graphical presentation of chromosomal fluorescence in situ hybridization patterns of the 3 Aegilops biuncialis accessions using pSc119.2- (red bands) and pAs1- (green bands) derived DNA probes.

Chromosome 1U was an SAT chromosome with two pSc119.2 sites on both telomeres and a pAs1 site on the secondary constriction. Chromosome $2 \mathrm{U}$ had one broad pSc119.2 site on the telomere of the short arm but no pAs1 sites on the whole chromosome. Chromosome $3 \mathrm{U}$ had two pSc119.2 sites on both telomeres. Chromosome $4 \mathrm{U}$ also had two pSc119.2 sites on both telomeres. The difference between $3 \mathrm{U}$ and $4 \mathrm{U}$ was in the arm ratio and relative arm length of the chromosomes. Chromosome 5U was a second SAT A. biuncialis chromosome. One pSc119.2 site occurred on the telomere of the secondary constriction and one pAs 1 site was present on the long arm. No band was observed on the telomere of the long arm. Chromosome $6 \mathrm{U}$ had 3 pAs1 sites; one on the centromere and two in the middle of the long arm. Chromosome $7 \mathrm{U}$ had $2 \mathrm{pSc} 119.2$ sites; one on the telomere of the short arm and another in the middle of the long arm. One pAs1 site was present in the middle of the long arm on chromosome 7U.

Chromosome $1 \mathrm{M}$ had one $\mathrm{pSc} 119.2$ site on the telomere of the short arm. It also had two pAs1 sites on the long arm - one on the telomere and another near the telomere. Chromosome $2 \mathrm{M}$ had two pAs1 sites; one on the telomere of the short arm and another on the long arm. Chromosome 3M had no sites on its entire length. Chromosomes 4M and 5M had one broad pSc119.2 site on the telomere of the long arm and short arm, respectively. Chromosome $5 \mathrm{M}$ also had two pAs1 sites; one in the middle of the short arm and another near the telomere of the long arm. Chromosome 6M had one pSc119.2 and one pAs1 site on the telomere of the long arm. Chromosome 7M had one pSc119.2 site on the long arm and two pAs1 sites on the short arm, one of which was on the telomere.

\section{DISCUSSION}

Detailed C-banding and FISH analyses of three $A$. biuncialis accessions were carried out and showed that $\mathrm{C}$-bands were present in all $A$. biuncialis chromosomes. Each chromosome of $A$. biuncialis displayed unique C-banding and FISH patterns that could be used for chromosome identification. Neither large structural rearrangements nor polymorphisms were observed in the C-banding and FISH patterns of the investigated accessions, indicating both close relationships and similar origins among the three $A$. biuncialis accessions.

The C-banding patterns of the three $A$. biuncialis accessions were generally similar to those of the A. biuncialis accessions reported by Badaeva et al. (2004), which belonged to type II chromosomes. For the individual component genomes, $\mathrm{U}^{\mathrm{b}}$ had intense centromere bands. This finding was consistent with that for the A. umbellulata karyotype reported by Friebe et al. 
(1995). The $\mathrm{M}^{\mathrm{b}}$ genome was somewhat different from the $A$. comosa subsp comosa karyotype $(2 n=2 x=14 \mathrm{MM})$ and notably different from the $A$. comosa subsp heldreichii karyotype $(2 n$ $=2 x=14 \mathrm{M}^{\mathrm{h}} \mathrm{M}^{\mathrm{h}}$ ) (Friebe et al., 1996).

Although no hybridization sites were observed in the $3 \mathrm{M}^{\mathrm{b}}$ chromosome, the FISH patterns for the $\mathrm{U}^{\mathrm{b}}$ and $\mathrm{M}^{\mathrm{b}}$ chromosomes of the three A. biuncialis accessions were also identified in terms of the $\mathrm{pSc} 119.2$ and $\mathrm{pAs} 1$ probes. The hybridization pattern of the $\mathrm{U}^{\mathrm{b}}$ genome was the same as those of four A. umbellulata accession diploids (Schneider et al., 2005) and similar to those recorded by Schneider et al. (2005) for the accessions we examined. The $5 \mathrm{U}^{\mathrm{b}}$ chromosome pattern differed. The $5 \mathrm{U}^{\mathrm{b}}$ chromosome in this study had one pAs1 site on the long arm, and no band was observed on the telomere of the long arm, whereas that of Schneider et al. (2005) had one pSc119.2 site on the telomere of the long arm and no band on the long arm. The hybridization pattern of the $\mathrm{M}^{\mathrm{b}}$ genome was variable for the $A$. comosa (MM) genome accession diploids on the $1 \mathrm{M}^{\mathrm{b}}, 3 \mathrm{M}^{\mathrm{b}}, 4 \mathrm{M}^{\mathrm{b}}$, and $6 \mathrm{M}^{\mathrm{b}}$ chromosomes but entirely different from the $A$. biuncialis genome $\left(\mathrm{U}^{\mathrm{b}} \mathrm{U}^{\mathrm{b}} \mathrm{M}^{\mathrm{b}} \mathrm{M}^{\mathrm{b}}\right)$ accession tetraploids on the $1 \mathrm{M}^{\mathrm{b}}, 3 \mathrm{M}^{\mathrm{b}}$, and $6 \mathrm{M}^{\mathrm{b}}$ chromosomes. In particular, the $1 \mathrm{M}^{\mathrm{b}}$ chromosome had only one pSc119.2 band on the telomere of the long arm and one pAs1 band on the telomere of the short arm. This result agreed with that of Badaeva et al. (2004), but disagreed with that of Schneider et al. (2005).

Our analyses confirmed that the $\mathrm{U}^{\mathrm{b}}$ genome in A. biuncialis originated from A. umbellulata (UU) diploid species, and that the $\mathrm{M}^{\mathrm{b}}$ genome of $A$. biuncialis may be a modified version of the M genome in A. comosa. The analysis further supported the hypothesis that most polyploid Aegilops species may have originated from limited hybridization events and share one or more common component genomes (Badaeva, 2002; Badeava et al., 2004).

In conclusion, the results of this study have provided further details on the characteristics of $A$. biuncialis chromosomes. The detailed karyotype information of $A$. biuncialis may be useful for standardized and accurate identification of $A$. biuncialis chromosomes either among different $A$. biuncialis accessions or in wheat- $A$. biuncialis hybrids.

\section{ACKNOWLEDGMENTS}

Research supported by grants from the National Key Basic Research Development Program (973 Program) of China (\#2009CB118300) and the earmarked fund for Modern Agroindustry Technology Research System of China (\#CARS-03-03B). We are grateful to Ms. Xianping Wang, Ms. Bin Li, and Dr. Qi Zheng for their valuable contributions to the FISH analysis.

\section{Conflict of interest}

The authors declare no conflict of interest.

\section{REFERENCES}

Badaeva ED (2002). Evaluation of phylogenetic relationships between five polyploid Aegilops L. species of the U-genome cluster by means of chromosomal analysis. Genetika 38: 799-811.

Badaeva ED, Amosova AV, Samatadze TE, Zoshchuk SA, et al. (2004). Genome differentiation in Aegilops. 4. Evolution of the U-genome cluster. Plant Syst. Evol. 246: 45-76.

Bedbrook JR, Jones J, O’Dell M, Thompson RD, et al. (1980). A molecular description of telometic heterochromatin in secale species. Cell 19: 545-560. 
Dhaliwal HS, Harjit-Singh and William M (2002). Transfer of rust resistance from Aegilops ovata into bread wheat (Triticum aestivum L.) and molecular characterisation of resistant derivatives. Euphytica 126: 153-159.

Friebe B and Heun M (1989). C-banding pattern and powdery mildew resistance of Triticum ovatum and four T. aestivum - T. ovatum chromosome addition lines. Theor. Appl. Genet. 78: 417-424.

Friebe B, Mukai Y and Gill BS (1992a). C-banding polymorphisms in several accessions of Triticum tauschii (Aegilops squarrosa). Genome 35: 192-199.

Friebe B, Schubert V, Blüthner W and Hammer K (1992b). C-banding pattern and polymorphism of Aegilops caudata and chromosomal constitutions of the amphiploid T. aestivum - Ae. caudata and six derived chromosome addition lines. Theor. Appl. Genet. 83: 589-596.

Friebe B, Jiang J, Tuleen N and Gill BS (1995). Standard karyotype of Triticum umbellulatum and the characterization of derived chromosome addition and translocation lines in common wheat. Theor. Appl. Genet. 90: 150-156.

Friebe B, Badaeva ED, Kammer K and Gill BS (1996). Standard karyotypes of Aegilops uniaristata, Ae. mutica, Ae. comosa subspecies comosa and heldreichii (Poaceae). Plant Syst. Evol. 202: 199-210.

Friebe B, Qi LL, Nasuda S, Zhang P, et al. (2000). Development of a complete set of Triticum aestivum-Aegilops speltoides chromosome addition lines. Theor. Appl. Genet. 101: 51-58.

Gerlach WL and Bedbrook JR (1979). Cloning and characterization of ribosomal RNA genes from wheat and barley. Nucleic Acids Res. 7: 1869-1885.

Gerlach WL and Dyer TA (1980). Sequence organization of the repeating units in the nucleus of wheat which contain 5S rRNA genes. Nucleic Acids Res. 8: 4851-4865.

Gill BS and Kimber G (1974). Giemsa C-banding and the evolution of wheat. Proc. Natl. Acad. Sci. U. S. A. 71: 40864090.

Makkouk K, Ghulam W and Comeau A (1994). Resistance to barley yellow dwarf luteovirus in Aegilops species. Can. J. Plant Sci. 74: 631-634.

McIntyre CL, Pereira S, Moran LB and Appels R (1990). New secale cereale (rye) DNA derivatives for the detection of rye chromosome segments in wheat. Genome 33: 635-640.

Molnár I, Gáspár L, Sárvári É, Dulai S, et al. (2004). Physiological and morphological responses to water stress in Aegilops biuncialis and Triticum aestivum genotypes with differing tolerance to drought. Funct. Plant Biol. 31: 1149-1159.

Mukai Y, Nakahara Y and Yamamoto M (1993). Simultaneous discrimination of the three genomes in hexaploid wheat by multicolor fluorescence in situ hybridization using total genomic and highly repeated DNA probes. Genome 36: 489-494.

Nagy ED, Molnar-Lang M, Linc G and Lang L (2002). Identification of wheat-barley translocations by sequential GISH and two-colour FISH in combination with the use of genetically mapped barley SSR markers. Genome 45: 12381247.

Rayburn AL and Gill BS (1986). Isolation of a D-genome specific repeated DNA sequence from Aegilops squarrosa. Plant Mol. Biol. Rep. 4: 102-109.

Resta P, Zhang HB, Dubcovsky J and Dvorak J (1996). The origins of the genomes of Triticum biunciale, T. ovatum, T. neglectum, T. columnare, and T. rectum (Poaceae) based on variation in repeated nucleotide sequences. Am. J. Bot. 83: $1556-1565$

Riley R, Chapman V and Johnson R (1968). Introduction of yellow rust resistance of Aegilops comosa into wheat by genetically induced homoeologous recombination. Nature 217: 383-384.

Schneider A, Linc G, Molnar I and Molnar-Lang M (2005). Molecular cytogenetic characterization of Aegilops biuncialis and its use for the identification of 5 derived wheat - Aegilops biuncialis disomic addition lines. Genome 48: 10701082.

van Slageren MWSJ (1994). Wild Wheats: A Monograph of Aegilops L. and Amblyopyrum (Jaub. \& Spach) Eig (Poaceae): A Revision of All Taxa Closely Related to Wheat, Excluding Wild Triticum Species, with Notes on Other Genera in the Tribe Triticcae, Especially Triticum: Wageningen Agricultural University, Wageningen.

Wang ZG, An TG, Li JM, Marta ML, et al. (2004). Fluorescent in situ hybridization analysis of rye chromatin in the background of "Xiaoyan No. 6". Acta Bot. Sin. 46: 436-442. 